\title{
Research on integrated education mode in college English teaching
}

\author{
Ying Shi \\ Qinhuangdao Institute of Technology, Qinhuangdao, Hebei, China
}

\begin{abstract}
College English teaching compares with the traditional English teaching from visual-audio-oral aspects. The integrated English teaching is mainly manifested in the target, systematicness, normalization, efficiency and effectiveness of the integrated English teaching quality. With the criteria of practicability, quality, integration and language features of the integrated teaching, this paper carries out quantifiable weight analysis of the integrated college English teaching content based on AHP model, and obtains proportion in various aspects.
\end{abstract}

Keywords: college English; integrated education; AHP

\section{INTRODUCTION}

After the reform and opening up, with the upgrading of China's comprehensive strength, the road of socialism with Chinese characteristics and target has an initial completion, which accelerates the pace of development in various industries. In today's pluralistic society, due to the nature of the industry, the rapid increase in the demand for English results in more and more English learners. Later, with the rise of various educational systems and institutions, China's English education industry becomes very complicated, but generally without a good practical benefit. Therefore, China should highlight the practical English education, and the reform of its status quo is very necessary. This paper will carry out the relevant research on the direction of the transition of China's practical English education, and find out the future reform strategies of China's practical English education.

In real life, there are gray fuzzy multi-criteria decision-making problems, and these problems are often present in the same system. The gray decision is a system resolution decision, which first defines a fuzzy set according to the indicator attributes, and gives the membership degree to the gray fuzzy relationship of each indicator. However, due to incomplete information, in the process of judging the degree of importance, there is a certain impact on the degree of importance. The gray fuzzy computing ignores the impact of gray on the degree of importance of criteria. Finally, this paper obtains the weight results of indicators, and also obtains the degree of importance of each judging criteria through the weight analysis. The analysis and improvement of English teaching quality based on this model plays a guiding role.

\section{DEFECT OF TRADITIONAL ENGLISH TEACHING}

In terms of China's primary and secondary education, the main teaching mode is: stimulate the students' leaning motivation $\rightarrow$ consolidate the knowledge learned $\rightarrow$ impart new knowledge $\rightarrow$ practice and use $\rightarrow$ inspect and evaluate. The education circle always explores a new teaching mode, but still has a great dependence on the teacher-centered teaching mode. Such an education mode allows teachers to get more initiative, and preferably organize and manage in the classroom, but it also limits the positive initiative and creativity of the students, so that the students could not fully develop their talents.

Nowadays, the education means aided with the computer multimedia teaching has a vigorous development, but also has an extensive application in discipline teaching. It has its own advantages, and the multimedia used in the classroom can fully mobilize the students' various senses, attract the students to devote to, and think deeply together.

Meanwhile, the multimedia can also impart teaching knowledge in accordance with hyperlinks way, so that the management and use of discipline knowledge is more convenient and rapid. English language has its fuzziness, which produces a higher requirement, so 
that the students should have a wealth of life experience as a foundation, as well as cultural literacy and a complete recognition structure of English.

Therefore, in the process of English language teaching, there is a need of targeted application according to the characteristics, and to create a convenient, fast and information-based teaching environment, in order to fully mobilize the visual sense and auditory sense, and allow the students to think positively. Moreover, a vivid teaching scenario is also conducive to their memory and understanding, and cultivation of the students' ability to think independently.

\section{INTEGRATED ENGLISH TEACHING QUALITY}

The integrated English teaching quality is mainly manifested in the target, systematicness, normalization, efficiency and effectiveness of the integrated English teaching quality. A better integrated English teaching is originated from joint function of each component, and reasonable organization of each teaching link, thus forming a good teaching quality assurance system.

The integration of English teaching quality is restricted by three factors, namely, the teaching objective factor, the teacher factor and the student factor, and it is a complex movement process with multiplex factors. Teachers play a leading role in the teaching process, is the organizer of the teaching process. Teachers play a leading role in the teaching process, which is the organizer of the teaching process, the direction of the teacher's control, the teaching content, the teaching method and the teaching process. And teachers' teaching ability has important influence on students' learning motivation, learning methods and ability. Teachers are the dominant factor restricting the quality of teaching. University management is one of the factors which restrict the quality of College English integrated teaching. Good teaching management can improve teachers' teaching enthusiasm and students' awareness of English learning.

\section{APPLICATION FEATURES OF INTEGRATED ENGLISH TEACHING}

\subsection{Business practicality of integrated English teaching}

From the reform and opening up to the $21^{\text {st }}$ century, English teaching mode also suffers from a series of reform. English teaching is first shifted from a minor subject to a major subject, with a continuous strengthening attention. In the process of continuous reform of English teaching mode, a number of different teaching methods and teaching requirements emerge out.
With the upgrading of China's comprehensive strength, it accelerates the pace of development in various industries. In today's pluralistic society, due to the nature of the industry, the rapid increase in the demand for English results in more and more practical English learners. The purpose of personnel training is to serve for the progress of society. Viewing from the economy, it is to develop a reasonable personnel training program for the economic development of the region, of which the most direct program is to achieve co-culture of school and enterprise, and make full use of resources according to regional characteristics, in order to promote the personnel training from the perspective of practice. As a universal language in the world, English links up with the world. The culture and economy all around the world achieve a common prosperity through English expression, so that other countries recognize the country's indigenous culture, and develop import and export trade. Therefore, English is not only a language, but also has its commercial nature. Training of practical English talents is not only confined to the relevant language teaching.

\subsection{Integrated English language teaching requirements}

English language teaching should be improved from the teaching methods and teaching mode. In the process of teaching, there is a need to arm their minds by the scientific knowledge, and also pay attention to the combination with theory and practice, in order to improve the students' manipulative ability from all aspects and the ability to solve the problems, and constantly improve their own quality. It embodies the actual existence of integrated teaching. As a modern teaching method, multimedia teaching adds a favorable assistant for teaching English language, provides the students with a rich and vivid teaching scenario that is close to real life, fully mobilizes the learning enthusiasm of the students, and improves the learning interest, in order to achieve a good learning effect.

\subsection{Language and cultural integration in the integrated English teaching}

Language not only carries the language information, and also is the carrier of culture. Therefore, in the process of translation, we must not only convey the meaning of the article itself, but also convey the cultural meaning behind it. The language in the literature is crafted and modified, so that the connotation of language becomes rich, and the translation requirement is high. Almost all of the literary translation should be faithful to the original work and faithful to the original author. The integrated English teaching conveys all aspects of the interpretation of the translated content from the image, audio and multiple angles, and also accumulates knowledge of foreign literature in the usual visual-audio-oral process, which is 
not only commonly used for college students, and even has an impact on the professional understanding of English.

Due to the limited experience of the students themselves, living environment is pure and simple. When they read classics under different times and different environment, they may be difficult to understand and perceive. The multimedia teaching can be used to display the pictures of the historical background and living environment, in order to promote the sensual use of the students, in-depth understanding and visual memory of literature. In the use of multimedia, we can carry out an overall treatment of the text, image and sound, so that different feelings can be complemented and promoted mutually, and greatly enrich the connotation of language and existing experience in real life. For example, in the classic literature, Romeo and Juliet, we can watch a movie or drama.

Due to the limited time in the classroom, something unimportant may be omitted in the process of explanation, such as the historical background and brief introduction of author. Now, due to the development of science and technology, these students can solve by their own. The integrated teaching facilitates the students to look up and organize materials. Moreover, in the learning process, they also learn other relevant knowledge, so that they know more about the content of work, which not only cultivates their manipulative ability, but also cultivates their ability to think independently. It is the quality of the students majored with English language, and also a perfect personality.

\section{WEIGHT ANALYSIS OF INTEGRATED ENGLISH TEACHING CONTENT}

The structure of integrated English teaching content is shown in the Figure 1.

This paper establishes the weight analysis of integrated English teaching content under the AHP model.

Target layer: integrated English teaching content.

Criterion layer: influence factors of the scheme. $x_{1}$ is the practicality of integrated teaching, $x_{2}$ is the quality of integrated teaching, $x_{3}$ is the integration of integrated teaching, $x_{5}$ is the language features of integrated teaching.

Scheme layer: English discussion, English homework, English test, question feedback.

This paper carries out the quantifiable weight assessment research and establishes AHP analysis model based on a large number of experts' experience, obtaining the weight calculation of English chat, English discussion, English homework, English test, question feedback and English resources:

There are many ways to calculate the weight vector of the judgment matrix, such as the definition computing, computer iteration, power method and harmonization method, of which a relatively simple method is harmonization method. Supposing that the weight vector of $n$ factors of judgment matrix is as follows:

$W=\left(w_{1}, w_{2}, w_{3} \cdots w_{n}\right)$

Then the judgment matrix is expressed as follows:

$A=\left(\begin{array}{cccc}w_{1} / w_{1} & w_{1} / w_{2} & \cdots & w_{1} / w_{n} \\ w_{2} / w_{1} & w_{2} / w_{2} & \cdots & w_{2} / w_{n} \\ \vdots & \vdots & \ddots & \vdots \\ w_{n} / w_{1} & w_{n} / w_{2} & \cdots & w_{n} / w_{n}\end{array}\right)$

According to the nature of the above matrix, all the column vectors of A can be normalized to obtain the matrix D.

$$
D=\left(\begin{array}{cccc}
a_{11} & a_{12} & \cdots & a_{1 n} \\
a_{21} & a_{22} & \cdots & a_{2 n} \\
\vdots & \vdots & \ddots & \vdots \\
a_{n 1} & a_{n 2} & \cdots & a_{n n}
\end{array}\right) \cdot\left(\begin{array}{cccc}
1 / \sum_{i=1}^{n} a_{i 1} & 0 & \cdots & 0 \\
0 & 1 / \sum_{i=1}^{n} a_{i 2} & \cdots & 0 \\
0 & \vdots & \ddots & \vdots \\
0 & 0 & \cdots & 1 / \sum_{i=1}^{n} a_{i n}
\end{array}\right)
$$

To solve a sum of each row of the normalized ma-

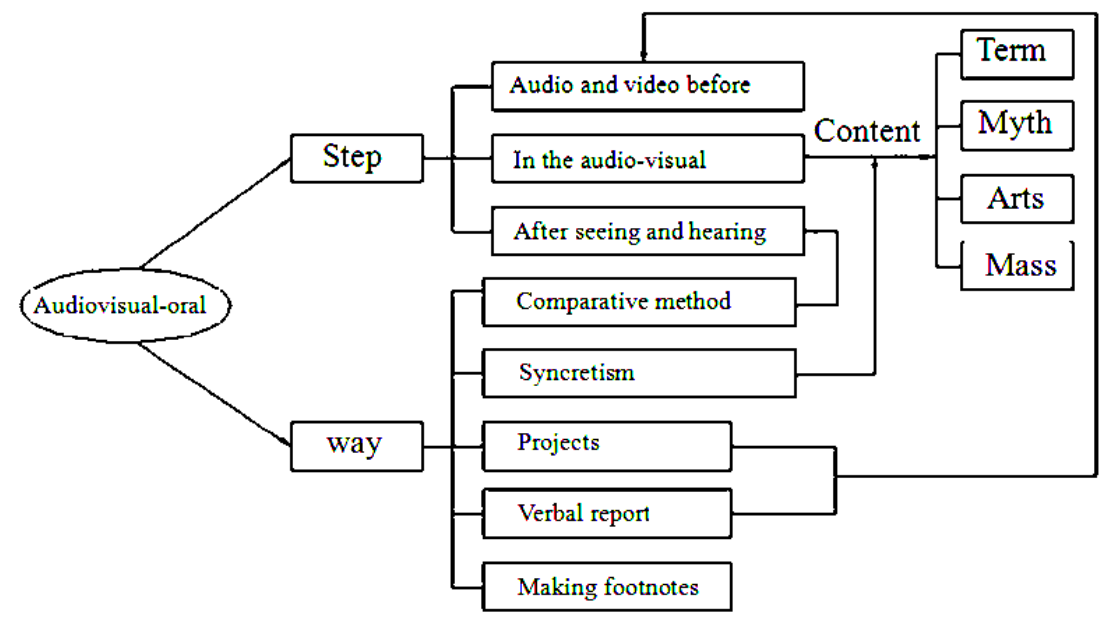

Figure 1. Integrated English teaching system 
trix, and then obtain the matrix E

$$
\begin{aligned}
& E=D \cdot\left(\begin{array}{llll}
1 & 1 & \cdots & 1
\end{array}\right)_{1 \times n}^{T} \\
& E=\left(\begin{array}{llll}
e_{11} & e_{12} & \cdots & e_{1 n}
\end{array}\right)^{T}
\end{aligned}
$$

To normalize the matrix $\mathrm{E}$, that is the weight vector.

$W=\left(\begin{array}{llll}w_{1} & w_{2} & \cdots & w_{n}\end{array}\right)=\left(\begin{array}{llll}e_{11} / \sum_{i=1}^{n} e_{i 1} & e_{12} / \sum_{i=1}^{n} e_{i 1} & \cdots & e_{1 n} / \sum_{i=1}^{n} e_{i 1}\end{array}\right)$

Calculate the maximum eigenvalue.

$\lambda_{\max }=\frac{1}{n} \sum_{i=1}^{n} \frac{(A W)_{i}}{w_{i}}$

Results of weight vector

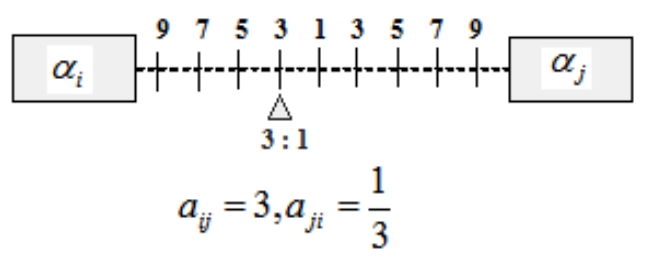

Figure 2. Scale from 1 to 9

The judgment matrix can be constructed according to the scale from 1 to 9 as shown in Figure 2, and reference and the principle of expert scoring. The greater the weight value is, the greater the degree of importance is. The judgment matrix:

$P=\left\{\begin{array}{cccc}1 & 1 / 3 & 4 & 6 \\ 3 & 1 & 2 & 5 \\ 1 / 4 & 1 / 2 & 1 & 3 \\ 1 / 6 & 1 / 5 & 1 / 3 & 1\end{array}\right\}$

After normalization of the judgment matrix $P$ :

$W^{(0)}=\left\{\begin{array}{l}0.302 \\ 0.302 \\ 0.236 \\ 0.170\end{array}\right\}$

$P W^{(0)}=\left\{\begin{array}{cccc}1 & 1 / 3 & 4 & 6 \\ 3 & 1 & 2 & 5 \\ 1 / 4 & 1 / 2 & 1 & 3 \\ 1 / 6 & 1 / 5 & 1 / 3 & 1\end{array}\right\}\left\{\begin{array}{l}0.302 \\ 0.302 \\ 0.236 \\ 0.170\end{array}\right\}=\left\{\begin{array}{l}2.49 \\ 2.31 \\ 0.76 \\ 0.43\end{array}\right\}$

$\lambda_{\max }^{(0)}=\frac{1}{4}\left(\frac{2.49}{0.302}+\frac{2.31}{0.302}+\frac{0.76}{0.236}+\frac{0.43}{0.170}\right)=4.21$

The eigenvectors obtained corresponding to the eigenvalues: $W=\left(\begin{array}{llll}0.25 & 0.14 & 0.55 & 0.06\end{array}\right)$

After consistency test ratio: $C R=0.025<0.1$

The calculation results pass the consistency test.
To do consistency test of the judgment matrix $B_{1}, B_{2}$, $B_{3}, B_{4}$, and obtain the weight vector, the calculation results from the target layer to the scheme layer are as follows.

Practicability of integrated teaching:

$\omega_{1}^{(1)}=\left(\begin{array}{lll}0.52 & 0.33 & 0.14\end{array}\right)^{\mathrm{T}}$

Quality of integrated teaching:

$\omega_{2}^{(2)}=\left(\begin{array}{lll}0.29 & 0.24 & 0.48\end{array}\right)^{\mathrm{T}}$

Integration of integrated teaching:

$\omega_{3}^{(3)}=\left(\begin{array}{lll}0.15 & 0.29 & 0.49\end{array}\right)^{\mathrm{T}}$

Language features of the integrated teaching:

$\omega_{4}^{(4)}=\left(\begin{array}{lll}0.48 & 0.29 & 0.24\end{array}\right)^{\mathrm{T}}$

Computing structure is as follows:

$$
\begin{aligned}
\omega^{(1)} & =\left(\omega_{1}^{(1)}, \omega_{2}^{(1)}, \omega_{3}^{(1)}, \omega_{4}^{(1)}\right) \\
& =\left\{\begin{array}{llll}
0.52 & 0.29 & 0.15 & 0.48 \\
0.33 & 0.24 & 0.29 & 0.29 \\
0.14 & 0.48 & 0.46 & 0.24
\end{array}\right\}
\end{aligned}
$$

$\omega=\omega^{(1)} \omega^{(0)}=\left\{\begin{array}{llll}0.37 & 0.13 & 0.23 & 0.26\end{array}\right\}$

\section{CONCLUSION ANALYSIS}

After calculation of AHP model, the weight of each program in the implementation of integrated English teaching materials is English discussion 0.37, English homework 0.13, English test 0.23, and question feedback 0.26. It indicates that the design of English discussion course, question feedback mechanism, English chat and making full use of the English resource is an effective way to improve English teaching. The design of the visual-audio-oral course should focus on the investment in these four aspects. In contrast, the traditional homework mode and examination are unable to effectively play a trigger role in the integrated visual-audio-oral teaching.

\section{CONCLUSION}

The integrated English education mode should be subject to English discussion and question feedback, and assisted by English chat and English resources, while English homework and English test should be the final test. Viewing from allocation of teaching hours, the allocation proportion of English chat, English discussion and making use of English resources 
should be 15:22:13. The focus is the question feedback mechanism and English homework investment.

\section{REFERENCES}

[1] Chen Yuhun, Dai Ruihua, Yang Xiaojiang, et al. 2004. Introduction of Higher Education Quality Assurance System. Beijing: Beijing Normal University Press.

[2] Zhang Wenzhong. 2005. Analysis of research status of domestic and foreign language learning motivation. Foreign Language World, (4).

[3] Niu Guixia. 2006. Research on college English classroom teaching quality evaluation system $[\mathrm{J}]$. Education and Occupation, 8

[4] Wu Shunxiang. 2006. Research on Combined Application for Fuzzy Set and Gray System Theory. Xiamen: Xiamen Human Science.

[5] Xu Qiuqin, Ren Weili. 2005. Exploration and analysis of college English teaching reform. China's Higher Education Research, 5 .

[6] Bi Fengchun. 2007. Analysis of improvement of college English teaching quality. Journal of Liaoning Administration College, (04).
[7] Li Qin. 2008. Fuzzy mathematics model and its application for comprehensive quality evaluation of college physical education teachers. Journal of Qinghai University, 26(4)

[8] Qi Wanli. 2011. Research on Moodle-based Collaborative Learning Practice of College English Course. Sichuan: Southwest University. Master's Thesis.

[9] Xia Li, Xia Guangfeng. 2012. Moodle-based college English teaching mode reform and practice research. Modern Education Technology, 21(4).

[10] Zhang Wanxin. 2012 Construction and practice research of integrated visual-audio-oral teaching mode of college English under Moodle-based platform. Guizhou province western society 2012 academic seminar proceedings.

[11] Liu Jing. 2013. Construction of Blended Learning Mode under Moodle-based Virtual Learning Environment. Jilin: Northeast Petroleum University. Master's Thesis.

[12] Tian Xingbin. 2013. Integrated English listening and speaking teaching design and practice under Moodle-based platform. Journal of Jilin University, 34(6).

[13] Zhang Wanxin. 2012. Research on Integrated Visual-audio-oral Teaching Mode of College English under Moodle-based Platform. Sichuan: Sichuan International Studies University, Master's Thesis. 